\title{
MANAJEMEN RANTAI PASOK KAYU GAHARU DI KALIMANTAN BARAT
}

\author{
Stefi Herda' ${ }^{1}$ an Anton Agus Setyawan \\ ${ }^{1)}$ Magister Manajemen Universitas Muhammadiyah Surakarta \\ 2) Fakultas Ekonomi dan Bisnis Universitas Muhammadiyah Surakarta \\ Jl. A. Yani Pabelan Kartasura Surakarta 57102 \\ email: Steffiherda@yahoo.com
}

\begin{abstract}
Abstrak
Penulisan ini bertujuan untuk menganalisis pasokan kayu gaharu, faktor penghambat pasokan kayu gaharu, dan jumlah yang dihasilkan dari satu pohon kayu gaharu dalam sekali pemanenan. Data diperoleh dari ketua kelompok tani perkebunan di Rasau Jaya, Petugas Penyuluh Lapangan di Rasau Jaya, Kepala Kantor Cabang di Rasau Jaya, dan pemilik perusahaan. Metode penelitian menggunakan metode kualitatif. Hasil penelitian menyimpulkan bahwa pasokan kayu gaharu pada bulan November 2015 sampai Agustus 2016 mengalami kekurangan bahkan kekosongan pasokan. Faktor yang menghambat ketersediaan pasokan yaitu faktor alam dan vaksin atau obat yang disuntikan ke pohon gaharu. Hasil panen yang didapat dari satu pohon gaharu sebanyak $5 \mathrm{~kg}$ per pohon dengan asumsi sekali panen mencapai 10 pohon gaharu dengan jumlah total kayu gaharu sebanyak $50 \mathrm{~kg}$.
\end{abstract}

Kata Kunci: Manajemen rantai pasok, kayu gaharu.

\begin{abstract}
This research aims to find out supply of aloes, aloes wood supply inhibiting factor, and the amount generated from a single tree in a single aloes wood harvesting. Data obtained from farmer groups plantation in Rasau jaya, extension agents in Rasau jaya, head of the branch office in Rasau jaya, and owner of the company. The research method using qualitative methods. The study concluded that the supply of aloes wood in November 2015 until August 2016 experienced a supply shortage even emptiness. Factors that inhibit the availability of the supply is natural factors and vaccines or drugs are injected to aloes tree. Yields obtained from the agarwood trees to $5 \mathrm{~kg}$ per tree with the assumption that once the harvest reached 10 with a total of tree aloes aloes wood as much as $50 \mathrm{~kg}$.
\end{abstract}

Keywords: Supply chain management, aloes wood.

\section{Pendahuluan}

Dewasa ini manajemen rantai pasok (supply chain management) tidak lagi dianggap sebagai hal baru bagi perusahaan. Banyak perusahaan telah menerapkan manajemen rantai pasok dalam bisnisnya untuk menambah efisiensi proses logistik perusahaan. Tujuan dari manajemen rantai pasok yaitu untuk meminimalisasi total biaya rantai pasok dalam pemenuhan kebutuhan tetap maupun tidak tetap. Total biaya meliputi biaya bahan baku dan biaya tambahan, biaya transportasi pengiriman, biaya fasilitas investasi, biaya produksi langsung dan tidak langsung, biaya persediaan, dan lain sebagainya. 
Menurut penelitian Wuwung (2013) manajemen rantai pasokan adalah sebuah sistem yang melibatkan proses produksi, pengiriman, penyimpanan, distribusi, dan penjualan produk dalam rangka memenuhi permintaan produk tersebut. Di dalam rantai pasokan meliputi seluruh proses dan kegiatan yang terlibat di dalam penyampaian produk hingga sampai ke tangan konsumen.

Menurut Heizer dan Render (2001) supply chain management bisa meliputi penetapan (1) pengangkut, (2) pentransferan kredit dan tunai, (3) pemasok (supplier), (4) distributor dan bank, (5) utang dan piutang, (6) pemenuhan pesanan, (7) pemenuhan pesanan, dan (8) membagi-bagi informasi mengenai ramalan permintaan, produksi, dan kegiatan pengendalian persediaan.

Menurut Poerwanto (2010) risiko-risiko yang dapat muncul dalam alur rantai pasok (supply chain), yaitu (1) Risiko gangguan pasokan, (2) Risiko kebutuhan dan rencana pasokan, (3) Risiko harga pembelian, (4) Risiko persediaan dan barang usang (obsolete), (5) Risiko proses yang tidak efisien, (6) Risiko keahlian dan kualifikasi sumber daya manusia. Implikasi dari kegagalan-kegagalan rantai pasokan akan menyebabkan timbulnya kerugian yang besar dan penundaan dalam pengiriman kepada pelanggan yang signifikan.

Adapun perkebunan adalah segala kegiatan yang mengusahakan tanaman tertentu pada tanah dan/atau media tumbuh lainnya dalam ekosistem yang sesuai; mengolah, memasarkan barang dan jasa hasil tanaman tersebut, dengan bantuan ilmu pengetahuan dan teknologi, permodalan serta manajemen untuk mewujudkan kesejahteraan bagi pelaku usaha perkebunan dan masyarakat.

Dalam Wikipedia, Perkebunan dibedakan menjadi dua menurut sifat intensifnya, yaitu agroforestri dan silvikultur (budidaya hutan). Perkebunan pemeliharaan memegang peranan penting, sementara dalam agroforestri dan silvikultur tanaman cenderung dibiarkan untuk tumbuh sesuai kondisi alam. Perkebunan hampir selalu menerapkan cara budidaya monokultur karena sifat intensifnya, kecuali untuk komoditas tertentu seperti lada dan vanili.

Penelitian ini bertujuan untuk mengetahui pasokan kayu gaharu, faktor penghambat pasokan kayu gaharu, dan jumlah yang dihasilkan dari satu pohon kayu gaharu dalam sekali pemanenan.

\section{Tinjauan Pustaka}

Menurut Heizer (2010) manajemen rantai pasokan (supply chain management) adalah integrasi aktivitas pengadaan bahan serta pelayanan, pengubahan bentuk menjadi barang setengah jadi dan produk akhir, serta pengiriman barang ke pelanggan. Seluruh aktivitas ini mencakup aktivitas pembelian dan pengalihdayaan (outsourcing), serta fungsi lain yang penting bagi hubungan antara pemasok dengan distributornya.

Menurut Storey (2006), fokus dalam penelitiannya yaitu strategi pasokan, strategi, dan manajemen rantai pasok ditujukan untuk strategi operasi. Salah satu fungsi dan proses yang sering hilang yaitu jaringan suplai. Sedangkan jaringan lainnya diperluas misalnya pendekatan yang berfokus pada kegiatan pembelian dan komponen dari kegiatan pasokan tersebut (komponen sistem).

Menurut Heizer (2010) perusahaan harus memutuskan suatu strategi rantai pasokan dalam rangka memperoleh barang dan jasa dari luar. Salah satu strategi adalah pendekatan bernegosiasi dengan banyak pemasok dan mengadu satu pemasok dengan pemasok yang lain. Strategi kedua adalah mengembangkan hubungan kemitraan jangka panjang dengan sedikit pemasok untuk memuaskan pelanggan. Strategi ketiga adalah integrasi vertical yang mana perusahaan dapat memutuskan untuk menggunakan integrasi balik secara vertikal dengan membeli pemasok tersebut.Variasi keempat adalah kombinasi sedikit pemasok dengan integrasi vertikal yang dikenal sebagai jaringan keiretsu. Di dalam keiretsu pemasok menjadi bagian dari kesatuan perusahaan.

Menurut Jebarus (2001) Secara umum penerapan konsep supply chain management dalam perusahaan akan memberikan manfaat 
yaitu kepuasan pelanggan, meningkatkan pendapatan, menurunnya biaya, pemanfaatan aset yang semakin tinggi, peningkatan laba, dan perusahaan semakin besar.

Menurut Ma'arif (2003) mengelola supply chain berarti merencanakan, mengorganisasikan, mengarahkan, dan mengontrol arus barang dari pemasok kepada konsumen. Ada beberapa hal yang dapat dilakukan untuk mengelola supply chain yaitu Penundaan atau pengunduhan, saluran perakitan, mengurangi atau menghentikan pengiriman, pemesanan seluruhnya, pembelian yang tidak menggunakan faktur, pemesanan elektronik dan transfer dana, pembelian yang tidak menyebabkan persediaan, standardisasi, membangun line of credit untuk pemasok, mengurangi bank float, koordinasi jadwal produksi dan pengiriman dengan pemasok dan distributornya, saling berbagi dalam penelitian pasar, dan mengoptimalkan penggunaan ruang-ruang kosong di gudang.

Menurut Cheny (2004), perusahaan melakukan berbagai inisiatif dan pendekatan untuk membahas berbagai isu yang terkait dengan rantai pasokan yaitu strategi pembelian, manajemen pasokan, logistik integrasi, dan penyediaan jaringan koordinasi.

Menurut Ma'arif (2003) terdapat dua hal yang harus diperhatikan dalam penerapan supply chain, pertama internal supply chain, yaitu melihat bisnis prosesnya dan melihat hal yang dapat di-improve dari sisi teknologi dan mengacu pada efisiensi dalam operation company. Kedua eksternal supply chain, beberapa komponen yang dibutuhkan dipasok dari luar sehingga masing-masing supplier mempunyai mata rantai.

Menurut Haming (2012) untuk menunjang kelancaran dalam penerimaan bahan dari pemasok dan penyaluran keluar kepada konsumen sarana angkutan adalah hal yang penting. Pihak perusahaan dan pemasok dalam memilih jenis angkutan yang akan digunakan perlu mempertimbangkan enam vaktor, yaitu transportasi apa yang tersedia, persediaan bahan dan produk yang akan diangkut, jarak pengangkutan, sifat dari produk yang akan diangkut, volume dari barang yang diangkut, administrasi, bea masuk atau cukai yang harus dibayar, risiko dan kerusakan terhadap produk, biaya handling dan pengepakan.

\section{Metode Penelitian}

Jenis penelitian ini adalah deskriptif dengan pendekatan kualitatif, yaitu menggunakan data berbentuk kata, skema, dan gambar. Menurut Moleong (2004:6) penelitian kualitatif adalah penelitian yang bermaksud untuk memahami fenomena tentang apa yang dialami oleh subjek penelitian secara holistik dan dengan cara deskripsi dalam bentuk katakata dan bahasa pada suatu kontes khusus yang alamiah dan dengan memanfaatkan berbagai metode alamiah.

Pada penelitian ini objeknya adalah manajemen rantai pasok. Objek penelitian menurut Maryadi et al. (2013) adalah variabel yang diteliti, baik berupa peristiwa, tingkah laku, aktivitas, ataupun gejala-gejala sosial lainnya.

Sumber data dalam penelitian ini didapat dari pemilik perusahaan, kepala kantor cabang, petugas penyuluh lapangan (PPL), dan petani di perkebunan. Menurut Moleong (2004), sumber data utama adalah katakata dan tindakan orang-orang yang diamati dan diwawancarai. Sumber data utama dicatat melalui catatan tertulis atau melalui perekaman, pengambilan foto atau film. Sumber data dalam penelitian ini diperoleh secara jelas dan pasti.

Menurut Sugiyono (2010) teknik pengumpulan data merupakan langkah yang paling strategis dalam penelitian karena tujuan utama dalam penelitian adalah mendapatkan data. Teknik pengumpulan data yang dipakai dalam penelitian ini adalah menggunakan metode wawancara dan dokumentasi.

Tahapan penelitian ini adalah (1) Pengumpulan data. Pengumpulan data adalah langkah pertama dalam melaksanakan suatu penelitian, di mana peneliti menggali sedalam mungkin data yang terkait dengan penelitian. Pada penelitian ini data yang dikumpulkan 
berupa hasil wawancara dengan pihak perusahaan, yaitu pemilik perusahaan, kepala kantor cabang, petugas penyuluh lapangan (PPL) dan petani di perkebunan, (2) Reduksi Data. Reduksi data yaitu merangkum data yang telah terkumpul kemudian mengarahkan serta mempertegas hal-hal penting tentang data tersebut sehingga menjadi suatu narasi sajian data. Berdasarkan data yang telah terkumpul, peneliti menyeleksi beberapa data yang tepat sehingga dapat digunakan untuk menjawab rumusan masalah, (3) Penyajian data. Tujuan dari penyajian data adalah agar penelitian menjadi lebih terarah serta mempermudah peneliti dan pembaca untuk memahami data yang ada. Menurut Sugiyono (2012), dalam penelitian kualitatif, penyajian data akan dilakukan dalam bentuk uraian singkat, bagan, hubungan antarkategori, flowchat, dan sebagainya. Berdasarkan pendapat tersebut, maka dalam penelitian ini data yang disajikan peneliti berupa uraian atau narasi hasil wawancara dengan responden, skema, dan gambar. (4) Penarikan Kesimpulan. Pada tahap ini, peneliti menarik kesimpulan berdasarkan data yang sudah disajikan sebelumnya untuk menjawab rumusan masalah tentang kondisi rantai pasokan, faktor penghambat, dan banyaknya jumlah gaharu yang dihasilkan dalam satu pohon.

\section{Hasil Penelitian dan Pembahasan}

\section{Analisis Rantai Pasok Kayu Gaharu}

Dari data yang telah diperoleh dapat diambil hasil yaitu, Kayu gaharu merupakan salah satu hasil perkebunan dengan harga jual yang ditentukan oleh kondisi pasar dan konsumen. Kayu gaharu suntikan bisa dipanen setelah mencapai umur 8 tahun dan telah melewati tahapan dalam proses penanaman, vaksinasi, dan perawatan pohon. Vaksinasi terhadap pohon bisa dilakukan setelah pohon mencapai usia 4 tahun. Sedangkan untuk kayu gaharu alam bisa dipanen setelah mencapai umur 20 tahun. Proses pemanenan pohon mulai penebangan sampai ke proses meng-curving membutuhkam waktu selama 6 minggu. Dalam satu kali pemanenan bisa mencapai 10 pohon, jumlah pemanenan ini disesuaikan dengan permintaan pembeli dan kebutuhan perusahaan. Untuk satu kali panen per satu pohon bisa menghasilkan kayu gaharu sebanyak 5 kilogram.

Faktor yang sering mempengaruhi kegagalan dalam ketersediaan pasokan dan pemanenan yaitu faktor cuaca dan vaksin yang disuntikan ke pohon. Faktor cuaca sangat mempengaruhi kondisi pohon gaharu. Cuaca panas berlebih menyebabkan pohon kekeringan dan cuaca hujan berlebih menyebabkan tumbuh jamur di pohon. 

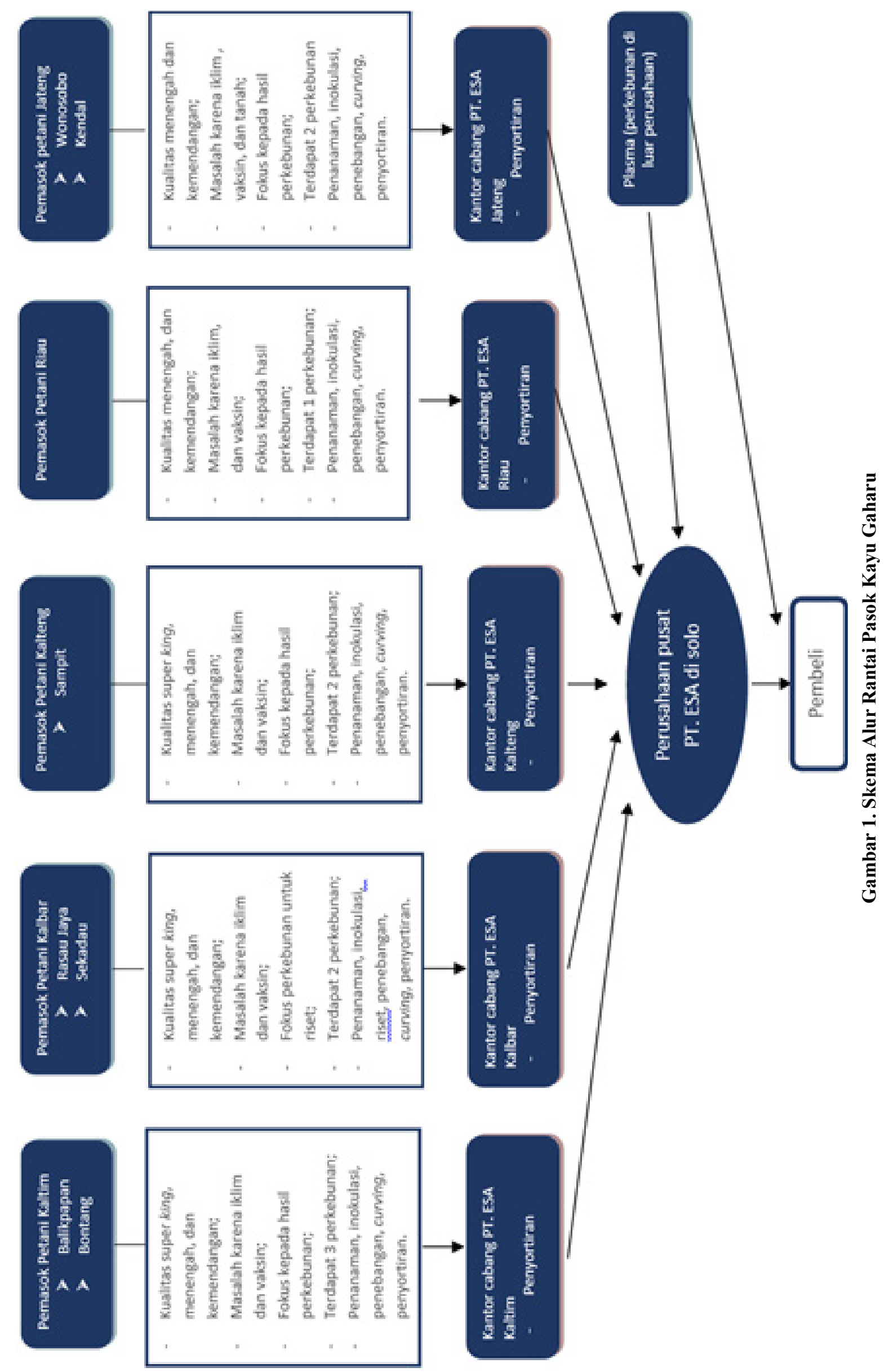
Dari skema alur distribusi di atas diketahui bahwa pasokan yang masuk ke perusahaan pusat berasal dari perkebunan yang berada di wilayah Bontang dan Balikpapan dikirim ke kantor cabang Kalimantan timur, wilayah Rasau Jaya dan Sekadau dikirim ke kantor cabang Kalimantan barat, wilayah Sampit dikirim ke kantor cabang Kalimantan tengah, wilayah Riau dikirim ke kantor cabang Riau, dan wilayah Wonosobo dan Kendal yang dikirim ke kantor cabang Jawa Tengah.

Kayu gaharu yang masuk dari petani ke kantor cabang terlebih dahulu akan disortir ulang di kantor cabang PT. ESA yang berada di masing-masing daerah. Penyortiran ini dilakukan sesuai dengan kebutuhan perusahaan yang meminta pengelompokan kayu berdasarkan kualitas dan berdasarkan dengan permintaan dari pembeli kayu gaharu.

Setelah sampai di perusahaan pusat maka perusahaan langsung mengirim barang kepada pembeli. Pembeli lokal dapat datang langsung ke perusahaan dan memilih kayu gaharu sesuai dengan keinginan atau melalui pemesanan dan langsung dikirim ke tempat tujuan pembeli. Adapun pembeli yang berasal dari luar negeri maka barang dikirim hanya sampai Jakarta kemudian barang dibawa oleh pembeli tersebut ke Negara masing-masing dengan perizinan yang dimiliki.

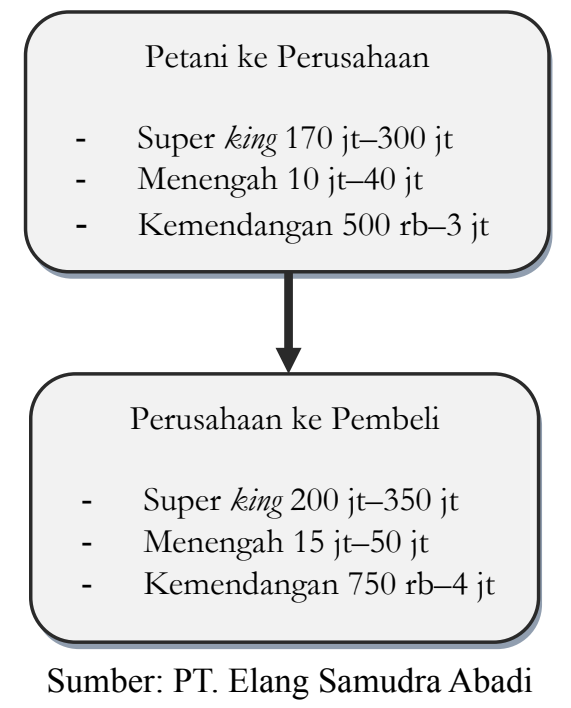

Gambar 2. Skema Alur Harga Kayu Gaharu

Tabel 1. Rata-Rata Harga Beli Terendah dan Tertinggi Kayu Gaharu

\begin{tabular}{|c|c|c|c|c|c|c|}
\hline \multirow{2}{*}{ Pelaku } & \multicolumn{2}{|c|}{$\begin{array}{c}\text { Kualitas Super King Per } \\
\text { kg }\end{array}$} & \multicolumn{2}{|c|}{$\begin{array}{c}\text { Kualitas Menengah Per } \\
\text { kg }\end{array}$} & \multicolumn{2}{|c|}{$\begin{array}{c}\text { Kualitas Kemendangan Per } \\
\text { kg }\end{array}$} \\
\hline & $\begin{array}{l}\text { Harga } \\
\text { Terendah }\end{array}$ & $\begin{array}{l}\text { Harga } \\
\text { Tertinggi }\end{array}$ & $\begin{array}{l}\text { Harga } \\
\text { Terendah }\end{array}$ & $\begin{array}{l}\text { Harga } \\
\text { Tertinggi }\end{array}$ & $\begin{array}{l}\text { Harga } \\
\text { Terendah }\end{array}$ & $\begin{array}{l}\text { Harga } \\
\text { Tertinggi }\end{array}$ \\
\hline Petani & 150 juta & 350 juta & 8 juta & 50 juta & 300 ribu & 4 juta \\
\hline Perusahaan & 200 juta & 400 juta & 10 juta & 55 juta & $500 \mathrm{ribu}$ & 5 juta \\
\hline
\end{tabular}

Sumber: PT. Elang Samudra Abadi

Harga rata-rata dari petani berkisar antara $170 \mathrm{juta}-300 \mathrm{juta} / \mathrm{kg}$ untuk kualitas super king, 10 juta-40 juta/kg untuk kualitas menengah, sedangkan untuk kelas kemendangan 300 ribu-3 juta/kg. Harga tersebut dijual oleh perusahaan dengan harga kualitas super king 200 juta-350 juta/kg, kualitas menengah 15 juta-50 juta/kg, sedangkan untuk kelas kemendangan 750 ribu-4 juta/kg. Harga tersebut ditentukan berdasarkan kondisi pasar kayu gaharu dan permintaan pembeli. Biaya transportasi pengangkutan kayu yang dikeluarkan dari perkebunan sampai ke kantor cabang rata-rata sebesar 3 juta dengan menggunakan truck pick up, sedangkan biaya pengangkutan dari kantor cabang ke perusahaan rata-rata $50 \mathrm{ribu} / \mathrm{kg}$ dengan mengunakan pengiriman jasa kargo.

\section{Pembahasan}

a. Kondisi Pasokan Kayu Gaharu di PT. Elang Samudra Abadi. Pasokan yang terdapat di perusahaan PT. Elang Samudra Abadi saat ini sedang mengalami kekosongan pasokan atau tidak terdapat kayu gaharu di perusahaan pusat. Hal ini terjadi karena perkebunan yang dimiliki oleh perusahaan belum bisa memanen kayu gaharu dari hasil perkebunan sendiri. Sering terjadinya kegagalan dalam panen kayu gaharu 
menyebabkan kekosongan pasokan. Kekosongan pasokan terjadi sejak bulan November 2015 hingga saat ini.

b. Faktor yang Menghambat Ketersediaan Pasokan Kayu Gaharu di PT. Elang Samudra Abadi. Kekurangan pasokan di perusahaan PT. Elang Samudra Abadi disebabkan oleh beberapa faktor. Faktor pertama karena cuaca yang ekstrem, jika terjadi hujan yang berlebih atau basah maka kayu gaharu akan mudah terkena jamur yang akan menyebabkan kematian terhadap pohon gaharu, sebaliknya jika iklim terlalu panas maka pohon akan mengalami kekeringan dan mati. Faktor yang kedua yaitu vaksin atau obat yang disuntikkan ke pohon gaharu, jika obat atau vaksin tersebut tidak cocok dengan pohon gaharu maka pohon akan mati. Tingkat kegagalan yang terjadi di perkebunan bisa mencapai 70\% bahkan lebih, jika sudah mencapai angka tersebut maka kayu gaharu tidak bisa dipanen.

\section{c. Pasokan yang Bisa Dihasilkan} dari Masing-Masing Pohon Kayu Gaharu PT. Elang Samudra Abadi. Kayu gaharu yang bisa dihasilkan dalam satu kali pemanenan sebesar $100 \%$ dari pohon gaharu bisa dimanfaatkan. Dari 100\%, untuk penyulingan minyak bisa diambil dari keseluruhan batang kayu. Total yang bisa dihasilkan dari kayu gaharu per batang bisa mencapai $5 \mathrm{~kg}$ kayu gaharu yang ada resinnya. Dalam sekali panen bisa mencapai 10 batang pohon dengan jumlah total gaharu yang ada resin sebesar 50 kg. Dari hasil panen kebun gaharu bisa menghasilkan kayu gaharu yang dikelompokan dalam beberapa kelas. Dimulai dari kelas yang super king bisa mencapai harga tertinggi sebesar 400 juta/kg, untuk kayu gaharu dengan kelas menengah bisa mencapai harga tertinggi $50 \mathrm{juta} / \mathrm{kg}$, sedangkan untuk kelas kemendangan dengan harga tertinggi 5 juta/kg.

\section{d. Pola Distribusi Kayu Gaharu PT.} Elang Samudra Abadi. Distribusi yang ada di perusahaan PT. Elang Samudra Abadi mencakup beberapa poin, yaitu aktivitas pendistribusian barang dari petani sampai ke perusahaan dan dari perusahaan kepada pembeli. Perusahaan melakukan pengiriman barang sesuai dengan peraturan yang telah ditentukan oleh dinas kehutanan sesuai dengan kuota yang telah ditentukan. Hal ini sejalan dengan teori Menurut Heizer (2010:4) manajemen rantai pasokan (supply chain management) adalah integrasi aktivitas pengadaan bahan serta pelayanan, pengubahan bentuk menjadi barang setengah jadi dan produk akhir, serta pengiriman barang ke pelanggan.

\section{e. Rantai Pasokan Kayu Gaharu PT.} Elang Samudra Abadi. Perusahaan PT. Elang Samudra Abadi melakukan aktivitas pengubahan barang mentah menjadi barang setengah jadi, yaitu dari bentuk pohon gaharu menjadi kayu yang sudah di curving dan bisa langsung diolah oleh pembeli. Perusahaan mengutamakan kualitas kayu gaharu yang dijual dan memanfaatkan waktu yang maksimal untuk melakukan perawatan sampai kepada pemanenan kayu gaharu. Sejalan dengan teori Menurut Heizer (2001:412) manajemen rantai pasok atau supply chain management merupakan kegiatan pengolahan kegiatan-kegiatan dalam rangka mendapatkan bahan mentah, mentransformasikan bahan 
mentah tersebut menjadi barang dalam proses dan barang jadi, dan mengirimkan produk tersebut ke konsumenn melalui sistem distribusi.

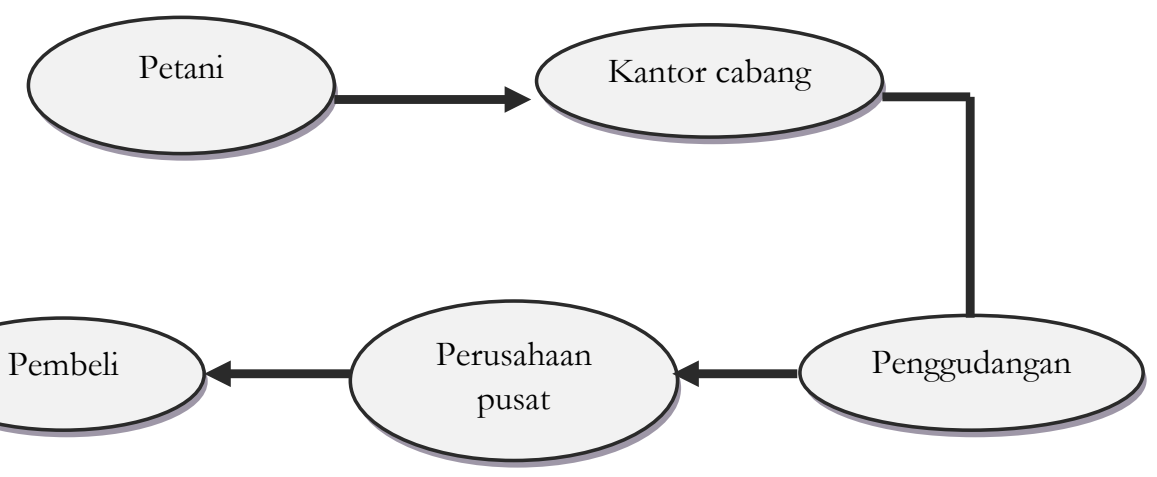

Gambar 3. Alur Rantai Pasok PT. Elang Samudra Abadi

Alur rantai pasok kayu gaharu PT. Elang Samudra Abadi dimulai dari petani kemudian dikirim ke kantor cabang, di kantor cabang dilakukan penggudangan, kemudian kayu gaharu dikirim ke perusahaan pusat di Solo dan dari kantor pusat kemudian dikirim kepada pembeli.

PT. Elang Samudra Abadi pada tahun 2013 menghasilkan kayu gaharu sebanyak 130 kilogram, pada tahun 2014 sebanyak 100 kilogram, dan pada bulan Januari 2015 sampai Oktober 2015 menghasilkan 50 kilogram. Pada bulan November 2015 sampai Agustus 2016 PT. Elang Samudra Abadi sedang mengalami kekurangan pasokan bahkan kekosongan dalam pasokannya.

\section{Simpulan}

Dari penelitian yang telah dilakukan dapat ditarik kesimpulan sebagai berikut:

a. Kondisi pasokan kayu gaharu PT. Elang Samudra Abadi pada saat ini sedang mengalami kekurangan bahkan kekosongan pasokan. Hal ini terjadi karena sering terjadinya kegagalan dalam pemanenan kayu gaharu. Kekosongan dalam pasokan ini terjadi sejak bulan November 2015 sampai Agustus 2016. Kegagalan dalam panen disebabkan oleh beberapa faktor yang dapat mempengaruhi pertumbuhan kayu gaharu bahkan kematian terhadap pohon gaharu. b. Faktor yang menghambat tersedianya pasokan kayu gaharu di PT. Elang Samudra Abadi yang pertama yaitu faktor alam, jika cuaca terlalu ekstrem hujan atau curah hujan terlalu tinggi maka akan menyebabkan kematian karena tumbuhnya jamur di pohon gaharu dan kayu gaharu akan tergenang air hujan. Setelah musim hujan dan terjadi cuaca panas yang berlebih maka akan terjadi kekeringan terhadap pohon gaharu dan pohon akan mati. Faktor yang kedua yaitu vaksin, jika vaksin yang disuntikan ke pohon gaharu tidak cocok dengan pohon, yaitu obat campuran di dalam vaksin tidak sesuai, maka pohon gaharu akan mati. Kedua faktor tersebut merupakan pemicu utama terjadinya kegagalan dalam pemanenan kayu gaharu.

c. Kayu gaharu yang bisa dihasilkan dari masing-masing pohon kayu gaharu di PT. Elang Samudra Abadi bisa mencapai 5 kilogram per batang kayu. Satu kali panen bisa mencapai 10 batang kayu dengan total pemanenan bisa mencapai $50 \mathrm{~kg}$ untuk kayu yang menghasilkan resin. Jumlah batang kayu gaharu yang dipanen oleh perusahaan sesuai dengan permintaan dari pembeli dan kebutuhan perusahaan.

Hasil penelitian mengenai manajemen rantai pasok kayu gaharu pada perkebunan PT. Elang Samudra Abadi Gaharu Green Gold 
di Kalimantan barat masih ada kekurangan yang peneliti temukan. Peneliti memberikan beberapa saran, antara lain:

a. Perusahaan lebih sering melakukan pengecekan dan pengontrolan terhadap pohon agar tidak terjadi kematian dan kerusakan terhadap pohon.

b. Perusahaan sebaiknya melakukan riset terhadap pohon untuk mengantisipasi faktor yang dapat menyebabkan kematian agar bisa diatasi sejak dini. c. Pemilik perusahaan lebih sering melakukan evaluasi pada setiap kantor cabang untuk mengetahui kekurangan dalam pengelolaan perkebunan yang dimiliki.

d. Perusahaan sering menjalin kemitraan dengan petani lokal untuk mengatasi kekurangan pasokan.

e. Perusahaan sering melakukan penelitian untuk mengembangkan teknologi dalam budidaya kayu gaharu.

\section{Daftar Pustaka}

Brito, LuizArtur dan Priscila Laczynski Miguel. 2011. Supply Chain Management Measurement and its Influence on Operational Performance. Vol. 4, No. 2. Hal 56-70.

Chen dan Paulraj. April 2004. Understanding Supply Chain Management Critical Research and a Theoretical Framework. Vol. 42, No. 1. Hal 131-163.

Gyfter.https://aisgyfterdotcom.wordpress.com/manajemen-rantai-pemasok-supply-chainmanagement/. Diunduh 30 Oktober 2015.

Haming, Murdifin dan Mahfud Nurnajamudin. 2012. Manajemen Produksi Modern. Jakarta: Bumi Aksara.

Kagira, Elias Kiarie. Et.all. 2012. Sustainable Methods of Addresing Challenges Facing Small Holder Tea Sector in Kenya: A Supply Chain Management Approach. Vol. 2, No. 2, Hal 75.

Ma'arif, Syamsul dan Hendri Tanjung. 2003. Manajemen Operasi. Jakarta: PT. Grasindo.

Maryadi, et al. 2013. Pedoman Penulisan Skripsi FKIP. Surakarta: BP-FKIP UMS.

Moleong, Lexy J. 2004. Metode Penelitian Kualitatif. Bandung: PT. Remaja Rosdakarya.

Poerwanto, Hendra. https://sites.google.com/site/operasiproduksi/manajemen-rantai-pasokan. Diunduh 19 November 2015.

Pusat penelitian dan pengembangan pertanian. http://perkebunan.litbang.pertanian. go.id/?p=3507. Diunduh 25 Februari 2016.

Putra, Nusa. 2011. Penelitian Kualitatif Proses dan Aplikasi. Jakarta: PT.Indeks.

Render, Barry dan Jay Heizer. 2001. Prinsip-Prinsip Manajemen Operasi. Jakarta: Salemba Empat.

2010. Manajemen Operasi. Jakarta: Salemba Empat.

Sartika, Ika. Pengembangan Model Rantai Pasok Produk Mudah Rusak dengan Mempertimbangkan Kualitas. 22 Oktober 2015.

Sharma, Vishal. 2013. Supply Chain Management of Rice in India: A Rice Processing Company's Perspective. Vol. 4, No, 1, Hal 25-36.

Somashekhar, Raju dan Hema Patil. 2014. Agriculture Supply Chain Management a Scenario in India. Vol. 04, No. 07. Hal 89-99. 
Stevenson, William J dan Sum Chee Chuong. 2014. Manajemen Operasi Perspektif Asia. Jakarta: Salemba Empat.

Storey, John et al. 2006. Supply Chain Management Theory, Practice and Future Challenges. Vol. 26, No. 7. Hal 754-774.

Sugiyono. 2010. Metode Penelitian Pendidikan Pendekatan Kuantitatif, Kualitatif dan R\&D. Bandung: Alfabeta.

.2012. Metode Penelitian Bisnis. Bandung: Alfabeta.

Suvittawat, Adisak. 2014. Production Analysis of Banana Supply Chain Management in Thailand. Vol. 2, No. 1, Hal 66-71.

Wuwung, Stevany Carter. 2013. Manajemen Rantai Pasokan Produk Cengkeh. Jurnal EMBA, Vol. 1, No. 3. Hal 230-238.

Yeboah, Nyamah Edmond. 2014. Agricultural Supply Chain Risk Identification-A Case Finding From Ghana. Vol. 5, No. 2, Hal 31-48. 